HUMANASE SOCIAIS

V.8 • N.3 • 2020 • Fluxo Contínuo

ISSN Digital: 2316-3801

ISSN Impresso: 2316-3348

DOI: $10.17564 / 2316-3801.2020 v 8 n 3 p 9-21$
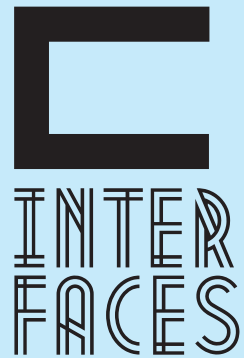

CIENTÍFICAS

\section{CORPO-IMAGEM NO FEMININO: INVESTIGAÇ̃̃O SOBRE MODOS DE DIZER AUDIOVISUAL EM DICÇÃO FEMININA}

\section{IMAGEN-CUERPO EN FEMENINO: INVESTIGACIÓN SOBRE FORMAS AUDIOVISUALES DE HABLAR EN DICCIÓN FEMENINA}

FEMALE BODY-IMAGE: RESEARCH ON AUDIOVISUAL WAYS OF SPEAKING IN FEMALE DICTION

\section{RESUMO}

0 presente artigo expõe algumas premissas categóricas e resultados parciais do projeto de mestrado intitulado $A$ imagem sob a dicção do feminino: uma proposta estética para a representação da mulher na linguagem audiovisual. A pesquisa propõe problematizar o predomínio de caracteres falocêntricos do modo de dizer hegemônico da linguagem audiovisual, além de apresentar, por meio das premissas do filme-ensaio, alternativas narrativas que reconduzam esse modo de dizer, no sentido de responder ao desejo visual dos olhos da mulher. Entender o que os olhos da mulher desejam ver como representação imagética de si e de seu desejo de imagem é o que se busca como objetivo Corpo-imagem final dessa investigação.

\section{PALAVRAS-CHAVE}

Corpo. Imagem. Feminino. Dicção. Filme-ensaio. 


\section{RESUMEN}

Este artículo expone algunos supuestos categóricos y resultados parciales del proyecto de maestría titulado "La imagen bajo la dicción de lo femenino: una propuesta estética para la representación de la mujer en el lenguaje audiovisual”. La investigación propone problematizar el predominio de los caracteres fagolocéntricos de la forma hegemónica de decir del lenguaje audiovisual, además de presentar, a través de las premisas de la película de ensayo, alternativas narrativas que lideran esta forma de decir, para responder al deseo visual de los ojos de la mujer. Comprender lo que los ojos de la mujer quieren ver como una representación imaginaria de sí misma y su deseo de imagen es lo que se busca como el objetivo final de esta investigación.

\section{PALABRAS CLAVE}

Cuerpo. Imagen. Mujer. Dicción. Ensayo cinematográfico.

\section{ABSTRACT}

This article exposes some categorical assumptions and partial results of the master's project entitled "The image under the diction of the feminine: an aesthetic proposal for the representation of women in audiovisual language". The research proposes to problematize the predominance of phallocentric characters of the hegemonic way of saying of audiovisual language, besides presenting, through the premises of the essay film, narrative alternatives that lead this way of saying, in order to respond to the visual desire of the woman's eyes. Understanding what the woman's eyes want to see as an imaginary representation of herself and her desire for image is what is sought as the ultimate goal of this investigation.

\section{KEYWORDS}

Body. Image. Female. Diction. Essay film. 


\section{INTRODUÇ̄̃̃O}

A mulher, seja como representação imagética, isto é, aquilo que se representa por meio de imagens, seja como corpo, indivíduo ou sujeito social, ocupa o lugar do "outro", o outro do homem construído social e historicamente como polo hegemônico em uma análise dicotômica simples. Esse "outro" também se inscreve ora como polo dominado, em uma dialética marxista, ora como polo anulado em uma dialética hegeliana. Em ambos os termos, para efeitos de afirmação de poder, a mulher guarda o lugar do silêncio, do murmúrio, do discurso afásico, geralmente, objeto de representação, raramente, sujeito ou autor da representação.

Esse silêncio ou murmúrio do feminino expressa-se no espaço privado da família, do lar, do aposento. O lugar da alcova, o espaço controlado do salão privado e os espaços de afazeres domésticos estabelecem o limite de atuação social da mulher que contrasta com a atuação pública do homem cidadão, principalmente a partir da ascensão da burguesia oitocentista. Como defende Sennett (1988), dentro de uma perspectiva de linearidade histórica, a invenção dessa mulher, restrita ao espaço privado da família, seja na condição de filha, esposa ou mãe, seria uma invenção moderna, uma invenção burguesa relativa a estética da mulher vitoriana oitocentista que será, na virada do fins-de-siècle XIX/XX, o paciente preferencial dos experimentos psicanalíticos de Freud, enquadradas nos diagnósticos de histeria e depressão. Vale colocar que, no Antigo Regime homens e mulheres eram iguais em sua condição de súditos subjugados ao poder do monarca.

Esse contexto social burguês, patriarcal e falocêntrico vai se desdobrar, ao longo do século XX, no sistema de representação da produção cinematográfica que coloca a mulher como um espelho que reflete o desejo do homem. Via de regra, a representação da mulher no cinema se configura como um reflexo a serviço do olhar desejante do homem.

A mulher, desta forma, existe na cultura patriarcal como significante do outro masculino, presa por uma ordem simbólica na qual o homem pode exprimir suas fantasias e obsessões através do comando linguístico, impondo-as sobre a imagem silenciosa da mulher, ainda presa a seu lugar como portadora de significado e não produtora de significado. (MULVEY, 2003, p. 438).

Nesta pesquisa propomos discutir por que motivos a produção imagética e cinematográfica tende a lidar com a imagem da mulher a partir de uma dicção que responde preferencialmente ao desejo do olhar do homem, expresso, principalmente, em atitudes marcadas por uma erotização do corpo da muIher a serviço do voyeurismo masculino. Sobre esse voyeurismo, assume-se que: “Embora o filme esteja realmente sendo mostrado, esteja lá para ser visto, as condições de projeção e as convenções narrativas dão ao espectador a ilusão de um rápido espionar num mundo privado” (MULVEY, 2003, p. 441).

Parte-se da necessidade de problematizar, por meio da dicção e possibilidades da linguagem audiovisual, o lugar reservado a representação da mulher na sociedade moderna ocidental, seja como expressão de um sujeito social, seja como expressão imagética. Para tanto, trata-se de trabalhar a tríade corpo/olhar/desejo, em que o corpo se projeta sobre os espaços permitidos e/ou ocupados pela mulher; 
o olhar, paradoxalmente, repudia e aceita a forma voyeurística falocêntrica que reifica o corpo da mulher e o desejo, igualmente, vai de encontro e ao encontro do discurso patriarcal que delimita o próprio lugar de expressão desse desejo. Especificamente sobre essa questão do desejo cabe perguntar: 0 que deseja uma mulher por meio do olhar? O que é desejar sob a ótica do feminino? O que especificaria o desejo ótico sob os termos da dicção do feminino? 0 que se quer ver sob a ótica do desejo feminino? Como empoderar a mulher por meio desse modo de olhar e propor uma imagem do feminino?

Para caminhar na direção de respostas as questões anteriores, esta pesquisa propõe pensar e experimentar, por meio do audiovisual, o que seria uma estética ou linguagem que atendesse ao desejo do olhar feminino. Tratou-se de produzir, a partir do conceito de filme-ensaio, um exercício de construção de uma dicção que ao mesmo tempo problematizasse e expressasse um modo de fazer imagem orientado pelo olhar feminino. Adotar o subgênero do filme-ensaio justifica-se por inscrever na produção cinematográfica uma narrativa vibrante e significativa, propondo a união da objetividade do documentário com a subjetividade do sujeito produtor/autor.

Os filmes-ensaios distinguem-se fundamentalmente de outras estratégias documentárias como forma de expressão e representação que necessariamente cedem o eu a acontecimentos, ações e objetos exteriores à autoridades de suas expressões e representações subjetivas. (CORRIGAN, 2015, p.35).

No que diz respeito a sua leitura e interpretação, a narrativa sob as prerrogativas do filme-ensaio não será nem linear, nem estável, visto que, o encontro da experiência dos acontecimentos que se desenrolam na tela com a subjetividade do próprio autor cria choques e lacunas que levam o telespectador a pensar e a refazer questionamentos, simultaneamente ao ato de ver e que, anteriormente, não estavam em sua mente, trazidos agora pelas entrelinhas do filme.

\section{CORPO}

A ideia que origina esse projeto diz respeito a fazer uma crítica ao discurso hegemônico das produções audiovisuais que representa o corpo da mulher como objeto de desejo masculino. Essa crítica contribui, não apenas ao escopo dos estudos de gênero e às estruturas falocêntricas, mas também promove o debate sobre qual seria o lugar da dicção de uma imagem que se expressa no feminino e busca atender ao desejo do olho da mulher, seja sobre outra mulher, seja sobre outra esfera desejante que se expresse em termos imagéticos. Não se trata apenas de pensar o que seria uma imagem que atendesse a um desejo feminino (lésbico ou hétero), mas algo que seria próprio do olhar feminino sobre o feminino ou sobre o masculino, invertendo os polos de dominação expressos na relação de representação imagética.

Desse modo, assume-se como sendo de grande relevância, para a afirmação de políticas de defesa da mulher na sociedade atual, a investigação sobre um novo paradigma imagético sob a dicção feminina. Por um lado, trata-se de propor um olhar não invasivo, que se nega a penetrar o corpo feminino a 
partir de um imaginário falocêntrico. Por outro lado, não se trata de assumir um ato ótico evasivo, que erra o corpo da mulher. Trata-se então de propor um outro modo de expressar o desejo pela imagem do outro, em um jogo cruzado de olhares em que se é sujeito e objeto ao mesmo tempo.

Para tanto, como modo de disseminar esse modo de produção imagética, propomos produzir exercícios que desenvolvem a produção desse olhar cinematográfico feminino. A base conceitual desses exercícios sustenta-se na discussão do lugar político do corpo na sociedade moderna. A discussão sobre a produção de poder e dominação, operando sobre o corpo de indivíduos e sociedades passa da instância individual/privada para a coletiva, sob uma dicção foucaultiana em que um problema privado é problematizado como um problema público. Foucault propõe o termo biopolítica para interpretar o modo como a população se movimenta e reage de acordo com determinadas posturas de dominação.

A biopolítica, surge no século seguinte e mobiliza um outro componente estratégico, a saber, a gestão da vida incidindo já não sobre os indivíduos, mas sobre a população enquanto população, enquanto espécie. Está centrada não mais no corpo-máquina, porém no corpo-espécie - é o corpo atravessado pela mecânica do vivente, suporte de processos biológicos: a proliferação, os nascimentos e a mortalidade, o nível de saúde, a longevidade - é a biopolítica da populaçãoo. (PELBART, 2003, p. 57).

Esse dispositivo de poder domina o coletivo por meio das restrições impostas sobre o indivíduo, uma vez que adquire poder administrativo na vida de vários corpos, ele também controla e domina o coletivo, sempre foi o objetivo primordial para a ordenação social, segundo os termos capitalistas e falocêntricos. Nessa ação de controle do corpo do indivíduo, visando o poder sobre a sociedade, uma característica desse controle ganha um valor exponencial, justamente porque é um ponto de encontro da disciplina e da biopolítica: a sexualidade.

A sexualidade perpassa as duas vertentes e ganha atenção em diversas camadas de exercício de dominação e poder. Sobretudo porque de um lado o sexo pertence às disciplinas corporais, o adestramento, à estética, à força e à energia vital, porém por outra ótica, ele também pertence ao controle do coletivo sob os termos da biopolítica. Como afirma Giddens (1993, p. 27): “o poder disciplinar supostamente produzia corpos dóceis, controlados e regulados em suas atividades em vez de espontaneamente capazes de atuar sobre o impulso do desejo".

Desse modo podemos observar que o sexo está claramente inserido em um processo de disputa política e ele é o ponto de convergência de diversas discussões de âmbito público e político. Não só o sexo, em particular, mas todo o corpo e sua condição de reprodução está introduzido num processo de politização crescente no meio social contemporâneo. A sexualidade e o corpo se tornaram tão importantes no contexto social que para Foucault, a nossa sociedade poderia ser denominada de "Sociedade da sexualidade".

Quanto a nós, estamos em uma sociedade do 'sexo', ou melhor, 'de sexualidade': os mecanismos de poder se dirigem ao corpo e à vida, ao que faz proliferar, ao que reforça a espécie, seu vigor, sua capacidade de dominar, ou sua aptidão para ser utilizada. Saúde, progenitura, 
raça, futuro da espécie, vitalidade do corpo social, o poder fala da sexualidade e para a sexualidade; quanto a esta, não é marca ou símbolo, é objeto e alvo. (FOUCAULT, 1988, p. 137).

Vale observar que nessa ótica, não se trata mais do corpo individual, o que vemos é um movimento que socializa e desloca a discussão sobre o corpo para a esfera pública e, por extensão, política.

Creio que a cultura ocidental foi surpreendida por uma espécie de desenvolvimento, de hiper-desenvolvimento do discurso da sexualidade, da teoria da sexualidade, da ciência da sexualidade, do saber sobre a sexualidade. (FOUCAULT, 2006, p. 58).

A politização do corpo no Ocidente se transformou num movimento de resistência com uma série de reivindicações em diversas classes, faixas etárias e gênero contra o poderio capitalista falocêntrico que usa o corpo para comunicar sua dominação social.

\begin{abstract}
Esse era um movimento que dizia que todo assunto é assunto de mulher, e todo lugar é lugar de mulher. Esse também era o movimento que se opunha ao concurso Miss América e ao Snuff* e entendia a conexão entre os dois. Ele entendia que objetificação sexual como uso e objetificação sexual como abuso eram duas faces da mesma moeda, e que a lógica de ambos é a de tornar uma pessoa em um objeto sexual. Miss America são as preliminares, tornando a mulher em um brinquedo. Snuff é a consumação do ato, tornando a mulher um cadáver. Esse era um movimento que retirava os rostos das mulheres de cartazes objetificantes. Ele marchava, ele fazia petições, ele organizava, ele tomou Wall Street e fez o Pentágono flutuar, ele processou, ele usou tudo que podia. Por que nós fizemos tudo isso? Nós fizemos, penso eu, porque éramos um movimento que valorizava a mulher. Mulheres importam (AMARA, 2017, on-line).
\end{abstract}

O feminismo, como maior ícone de resistência e combate à dominação falocêntrica, atua também por meio do choque que o nu feminino é apresentado na sociedade, de maneira não manipulada e auto referenciada.

Esse modo de lidar com o corpo nu adotado por certos movimentos de marca feminista opera na contramão do que toda a história da indústria cinematográfica hegemônica propôs até hoje. 0 cinema e demais suportes audiovisuais produziram imagens de forma massificada: ao acompanhar as lentes objetificadoras do cinema, os espectadores, homens e mulheres, também reificaram seus objetos de desejo, permeando e contaminando a experiência cotidiana do corpo, com essa experiência visual fabricada para o olho. Sob tal estado de encantamento já não se permite o discernimento do que se constrói como realidade frente o que se diz imagético, ou ainda, o que se experimentaria em termos físicos e o que se experimentaria em termos virtuais.

Não foi a realidade que invadiu a nossa imagem: foi a imagem que invadiu e destruiu a nossa realidade (ou seja, as coordenadas simbólicas que determinam o que sentimos como realidade). [...] o sujeito se submete ao efeito da carência simbólica que revela o 
limite da realidade diária. Atravessar a fantasia no sentido lacaniano é ser mais profundamente exigido pela fantasia do que em qualquer outra época, no sentido de ter uma relação cada vez mais íntima com o núcleo real da fantasia que transcende a imaginação. (ZIZEK, 2003, p. 33-34).

Richard Sennett (1999), propõe que o corpo se comporta no espaço urbano/público, estabelecendo relações políticas e morais com esse espaço. Seguindo essa linha de raciocínio, entendemos que a sociedade ocidental estabeleceu níveis de tolerância variados em relação ao que pode ou deve caber a uma mulher em sociedade. Por exemplo, na Revolução Francesa, quando o busto feminino de Marianne é o principal símbolo de luta, deixa-se uma possibilidade interpretativa desse signo de valorização da imagem feminina nua, moderna e revolucionária.

A República da virtude não concebe que as mulheres ocupem o espaço público; a virtude feminina é doméstica, privada, discreta' [...] A revolução tentou construir, na cidade, locais em que os cidadãos pudessem expressar sua liberdade, dando à luz às virtudes de Marianne - liberdade, igualdade, e fraternidade, massa liberdade no espaço conflitava com a liberdade no corpo. (SENNETT, 1999, p. 239-241).

\section{A IMAGEM}

Assim, parte-se da ideia de que a imagem da mulher foi construída a partir de certos estereótipos pré-estabelecidos pelos homens e enraizados na sociedade como verdades hegemônicas. Cultua-se o corpo feminino de modo que a imagem e o corpo não se distinguem mais. Isto é, ao se falar de muther é gerada na mente uma imagem padrão do corpo feminino. A partir dessa premissa, vinculam-se algumas imagens paradigmáticas como, por exemplo, a da "mulher frágil e imaculada", a "matriarca dona de casa" e a "fêmea fatal". Se as duas primeiras estão diretamente enquadradas aos ideais conservadores do patriarcado e do falocentrismo, a última gera reações ambíguas. Essa construção da "fêmea fatal" cola-se muitas vezes na imagem da prostituta, que não corresponde ao pudor da sociedade machista, tornando-se uma ameaça ao padrão.

"Vista como maligna por sua sexualidade explícita, essa mulher precisa ser destruída [...] a femme fatale deve ser assassinada. O revólver ou a faca assumem o lugar do falo que deve eliminando-a, dominá-la” (KAPLAN, 1995, p. 22). Tais construções imagéticas, com o desenvolvimento da indústria de produção em massa de imagens, se tornaram referenciais de beleza e desejo para o olhar masculino, seja nas telas dos cinemas, seja na televisão, nas revistas ou qualquer outro veículo de comunicação de massa.

A mulher, desta forma, existe na cultura patriarcal como significante do outro masculino, presa por uma ordem simbólica na qual o homem pode exprimir suas fantasias e obsessões através do comando linguístico, impondo-as sobre a imagem silenciosa da mulher, ainda presa a seu lugar como portadora de significado e não produtora de significado. (MULVEY, 2003, p. 438). 
Porém, há uma forma de produção de imagens não hegemônica, não industrial, que se opõe a isso. Um formato de documentário com uma dicção mais subjetiva, que combina a expressão do "pessoal" com a "realidade" da experiência pública em uma narrativa epistemológica que se desloca e desliza no entre do cinema, da música e da literatura.

Ao contrário dos documentários em formatos clássicos, o filme-ensaio busca produzir um diálogo aberto entre o espectador e o diretor, visto que a dicção do filme-ensaio expressa uma experiência aberta, sujeita a interpretações que necessitam do olhar do espectador para dizer algo. Timothy Corrigan (2015) relata que em 1930 os ensaios fotográficos tiveram forte apelo na sociedade, gerando uma certa tensão com os textos verbais da literatura, o que foi se resolvendo em meados de 1940 com o surgimento do Filme-ensaio e a sua capacidade de comentar a subjetividade do texto com sua "câmera-ensaio", não somente reportando, mas interpretando os fatos em um texto implícito que perturba e cria um filme em uma dicção de resistência intelectual de que nem tudo precisa ser mostrado no filme para ser entendido.

Se a atividade infere movimento não resolvido, em vez de estrutura formal, e sugere vários tipos de efeito (sobre si, sobre o mundo, etc.), a atividade do pensamento ensaístico, aqui, descreve uma consciência de reflexão e decifração que a distingue de outras atividades mentais (prazer, fantasia), apesar de esses muitas vezes serem os próprios temas dessa perspectiva ensaística. (CORRIGAN, 2015, p. 39).

Tal formato gerou e ainda gera um certo incômodo em espectadores não habituados ao formato, porque por mais que o ensaio seja sobre o cotidiano, a visão idiossincrática do diretor se mistura com as experiências públicas, propondo um ponto de vista sobre o mundo, como uma crônica em suporte audiovisual. Esse formato, em vez de criar uma estabilidade entre a subjetividade e a experiência pública, gera inquietação e lacunas, induzindo o espectador a pensar com o filme por meio de um diálogo participativo. E por isso a importância da escolha do formato, visto que a temática de uma nova dicção do feminino ainda permanece com lacunas e inquietação para se estabelecer no exercício de uma nova perspectiva audiovisual.

De posse dessas premissas do filme-ensaio, propõe-se um exercício audiovisual, por meio de entrevistas com profissionais mulheres do audiovisual sobre a problematização e construção da representação do corpo feminino para um público interessado nessa nova perspectiva de olhar e produzir imagem. Trata-se então de entender por meio das entrevistas as diversas representações do que seria essa nova dicção imagética do feminino. A ideia é aplicar um questionário dirigido a um grupo pré-selecionado de mulheres da área audiovisual alagoano, para entender o que seria para elas falar por meio das imagens sob a dicção de uma perspectiva feminina.

A pesquisa adota a princípio o método dedutivo, partindo do pressuposto de que a sociedade ocidental é estruturada sobre as alcunhas falocêntricas e patriarcalistas. Por meio de uma abordagem qualitativa, colocada em prática por meio de entrevistas semiestruturadas, busca-se entender o que esse grupo de mulheres pensa sobre a produção audiovisual e como se sentem em relação ao espaço destinado à mulher enquanto produtora, atriz, profissional técnica ou telespectadora. 
Para selecionar o público entrevistado, será feita uma triagem em produtoras, agências, equipes de produção e elencos de filmes locais, buscando mulheres que estão envolvidas na produção audiovisual alagoano. As mulheres escolhidas serão contatas para a realização das entrevistas. Os resultados das entrevistas serão a base para o desenvolvimento do roteiro colaborativo de um filme-ensaio produzido com a interpretação das percepções durante as entrevistas.

0 processo de produção audiovisual, partindo do resultado das entrevistas, falas, expressões e sentimentos das entrevistadas, deve conseguir expressar - por meio dos ângulos de câmera, enquadramentos, iluminação, textura e edição das imagens - a dicção feminina em um filme-ensaio que concretizará o objetivo final desta pesquisa.

\section{CONCLUSÃO}

Por hora o que se tem como resultado parcial de nossas investigações se expressa na realização de um filme ensaio em que se busca materializarem imagem e som as questões do corpo e da representação da mulher sob a dicção de uma imagem que se propõe falar para o desejo feminino.

Na produção do filme buscou-se trazer aspectos sociais vivenciados pelas mulheres em sociedade expressa em forma de alegorias. 0 filme se passa no sertão alagoano e a primeira alegoria trazida é um Jaraguá .

Trata-se de um brinquedo popular típico do sertão que assusta por meio de sua aparência e tamanho. No filme, o Jaraguá perde sua força e morre, expressando a força quimérica da mulher subjugada às condições do patriarcalismo endêmico da região. O Jaraguá é construído como algo bestial, assim como a mulher que se empodera ou busca se empoderar. Será a incompreendida, louca, complicada, a besta que precisa ser morta ou enjaulada.

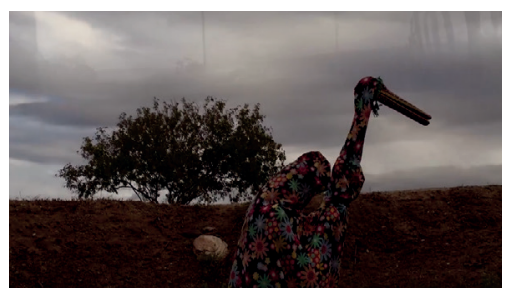

Fonte: Acervo Pessoal

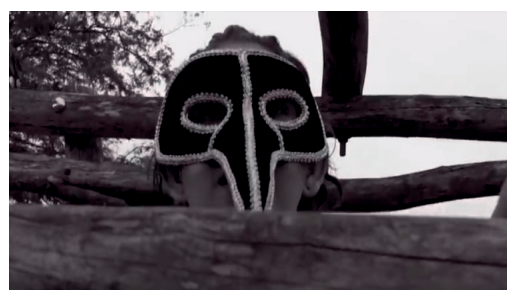

Fonte: Acervo Pessoal

3 Vindas para o Brasil, as festas populares em comemoração ao ciclo natalino, incluíram no folguedo animais característicos dos presépios: boi, burrinha, etc e personagens totêmicos e míticos europeus, ameríndios ou africanos: Sereia, Onça, Jaraguá, Caipora, Folharal, etc. O Jaraguá, que em Tupi significa “Bicho que Pega”, é uma das personagens do Boi de Mamão (Santa Catarina) e de alguns reisados pelo Brasil. Em Pernambuco, o Jaraguá é figura sempre presente no Baile do Menino Deus na cidade de Recife. O Jaraguá compõe-se, geralmente, de uma caveira de cavalo coberta com tecido de chita, com as mandíbulas articuladas por meio de um fio que tem a função de bater-lhe os dentes (ALETRIA, 2017, on-line).). 
Isso nos leva à segunda alegoria do filme, o pássaro negro enjaulado. Uma forma de representar o encarceramento da mulher na sociedade patriarcal. 0 poder falocêntrico encurta e delimita os espaços sociais da mulher, obrigando-a a caber ali com seus anseios e desejos. A mesma alegoria é usada em outro momento em que o pássaro se encontra em cima de uma árvore. Espreita apavorado o que se passa ao seu redor.

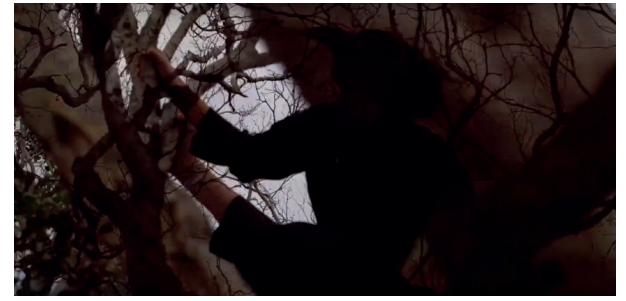

Fonte: Acervo Pessoal

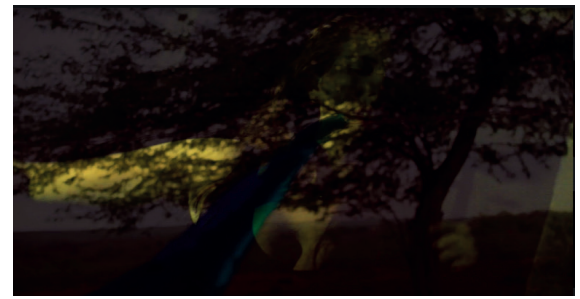

Fonte: Acervo Pessoal

Ao mesmo tempo em que expressa medo, angústia e desconforto tenta assustar as ameaças que lhe cercam com uma postura estranha e desafiadora. Quando retratada como santa e musa, a alegoria que se funde à imagem da Vênus de Botticelli busca expressar o tabu da santificação da mulher que lhe cobra pureza e virgindade perante a sociedade, uma mulher que não deve ter desejos ou prazeres. Essa alegoria configura-se também como ponto de virada do filme. Para expressar o gozo feminino sem tabus, o filme foca no tema da menstruação como poder de conexão entre mulheres e como forma de enfrentar o tabu, imposto em inúmeras culturas ocidentais e orientais, que associa o sangue da menstruação à sujeira, impureza, doença, anomalia, coisa repulsiva, execrável, monstruosa. Nessas cenas, o sangue é visto como parte do gozo feminino, em que a mulher não se sente enojada com uma experiência cotidiana e fisiológica, natural do seu próprio corpo.

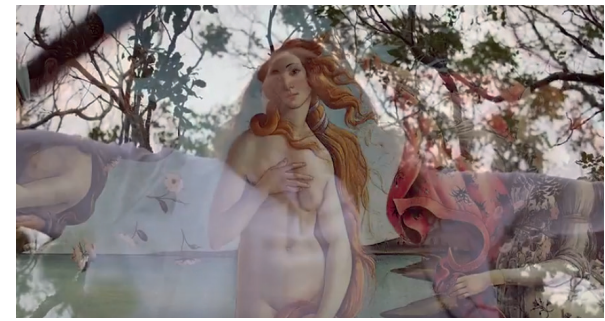

Fonte: Acervo Pessoal

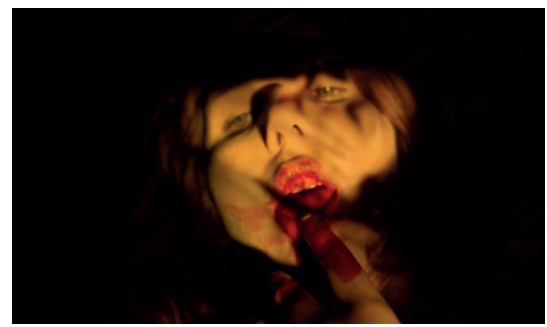

Fonte: Acervo Pessoal 


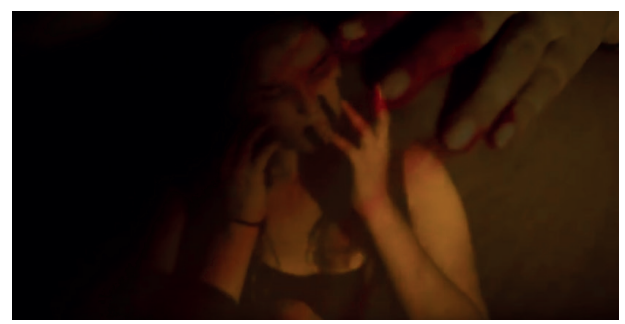

Fonte: Acervo Pessoal

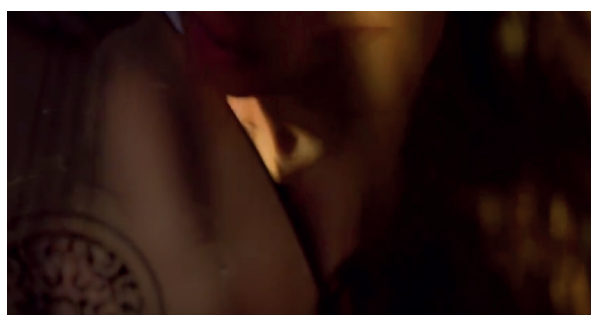

Fonte: Acervo Pessoal

A pintura com o sangue é tratada no filme como uma representação da delicadeza do toque feminino juntamente com o toque do alaúde no ideal de reproduzir mais uma alegoria ligada ao toque feminino com outra mulher ou com ela mesma. Na alegoria do gozo sem tabus se enfatizam movimentos lentos, sugerindo as diferenças de velocidade entre o gozo da mulher e do homem, o que raramente é contemplado na dicção audiovisual.

A montagem do filme, com imagens sobrepostas e uma trilha sonora desconfortável, busca produzir reflexões subversivas e transformadoras. Para tanto, assume-se a dicção de filme-ensaio em que propositalmente se abrem lacunas para que o espectador as interprete com base em suas idiossincrasias, valores, experiências. Esse filme-ensaio configurou-se como a primeira experiência audiovisual resultante da pesquisa, em que se investiga aspectos da dicção cinematográfica sustentada por conceitos e categorias da imagem sob orientação de uma estética feminina que se expressa no sentido de atender o desejo ótico da mulher e do feminino pelo feminino.

\section{REFERÊNCIAS}

ALETRIA Editora. Muito além do Papai Noel: personagens do natal. 17 dez. 2017. Disponível em: https://www.aletria.com.br/blog?single=Muito-alem-do-Papai-Noel-Personagens-do-NatalBrasileiro. Acesso em: 25 set. 2019.

AMARA, Ariana. Liberalismo e a morte do feminismo: Era uma vez um movimento de mulheres. Medium, 4 out. 2017. Disponível em: https://medium.com/qg-feminista/liberalismo-e-a-morte-dofeminismo-parte-1-ad25df49542d. Acesso em: 21 nov. 2018.

CORRIGAN, Timothy. 0 filme-ensaio: desde Montaigne e depois de Marker. Campinas, São Paulo: Papirus, 2015.

FOUCAULT, Michel. História da Sexualidade I. A vontade de saber. Rio de Janeiro: Edições Graal, 1988.

FOUCAULT, Michel. Ética, sexualidade, política. Rio de Janeiro: Forense Universitária, 2006. 
GIDDENS, Anthony. A transformação da intimidade. São Paulo: UNESP, 1993.

KAPLAN, Ann. Women \& Film. Both Sides of the Camera. London: Methuen, 1995.

MULVEY, Laura. Prazer visual e cinema narrativo. In: XAVIER, Ismail. A experiência do cinema. Rio de Janeiro: Edições Graal, 2003.

SENNETT, Richard. 0 declínio do homem público: as tiranias da intimidade. Rio de Janeiro: Companhia das Letras, 1988.

SENNETT, Richard. Carne e pedra: o corpo e a cidade na civilização ocidental. Rio de Janeiro: Companhia das Letras, 1999.

SPINK, Mari Jane. Pessoa, indivíduo e sujeito: notas sobre efeitos discursivos de opções conceituais. In: SPINK, M. J. P.; FIGUEIREDO, P.; BRASILINO, J. (Org.). Psicologia social e pessoalidade [online]. Rio de Janeiro: ABRAPSO, 2011. Disponível em SciELO Books http://books.scielo.org. Acesso em: 17 abr. 2017.

ZIZEK, Slavoj. Bem-vindo ao deserto do Real! São Paulo: Editora Boitempo, 2003. 


\begin{abstract}
1 Mestranda do Programa de Pós-Graduação em Sociedade, Tecnologia e Políticas Públicas - Centro Universitário Tiradentes - UNIT/AL; Graduada em Comunicação Social/ Publicidade e Propaganda Públicas - Centro Universitário Tiradentes - UNIT/AL. E-mail: falecomalore@gmail.com

2 Professor do Programa de Pós-Graduação em Sociedade, Tecnologia e Políticas Públicas, Centro Universitário Tiradentes - UNIT/AL; Doutor em Planejamento Urbano e Regional pelo Instituto de Planejamento e Pesquisa Urbano e Regional - IPPUR/UFRJ; Pós-Doutor em Cinema pelo Programa de Pós-Graduação em Cinema da Universidade da Beira Interior (Covilhã, Portugal). E-mail: walclerjunior@ hotmail.com
\end{abstract}

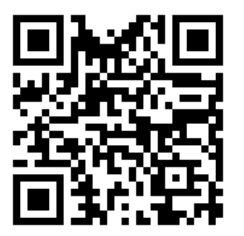

A autenticidade desse artigo pode ser conferida no site https://periodicos. set.edu.br

\section{(ㄷ) (1) (2)}

Este artigo é licenciado na modalidade acesso abertosob a Atribuição-Compartilhalgual CC BY-SA

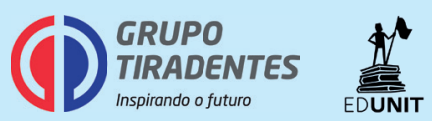

